\title{
Capecitabine-associated hand-foot-skin reaction is an independent clinical predictor of improved survival in patients with colorectal cancer
}

\author{
R-D Hofheinz ${ }^{*, 1}$, V Heinemann ${ }^{2}$, LF von Weikersthal ${ }^{3}$, RP Laubender ${ }^{4}$, D Gencer ${ }^{1}$, I Burkholder ${ }^{5}$, A Hochhaus $^{6}$ \\ and S Stintzing ${ }^{2}$
}

'TagesTherapieZentrum (TTZ), Interdisciplinary Tumour Centre, University Hospital Mannheim, University of Heidelberg, Theodor-Kutzer-Ufer I-3, Haus 9, Mannheim 68167, Germany; ${ }^{2}$ Department of Haematology and Oncology, Comprehensive Cancer Center, Klinikum Grosshadem, University of Munich, Munich, Germany; ${ }^{3}$ Oncology Practice, Amberg, Germany; ${ }^{4}$ Institute of Medical Informatics, Biometry, and Epidemiology, University of Munich, Munich, Germany; ${ }^{5}$ STABIL, Zweibrücken, Germany; ${ }^{6}$ Department of Hematology and Oncology, Jena University Hospital, Jena, Germany

BACKGROUND: Hand-foot-skin reaction (HFSR) is an adverse event frequently observed during treatment with capecitabine (cape). In the present analysis, we sought to evaluate the potential association of HFSR and survival in German patients with metastatic colorectal cancer and locally advanced rectal cancer treated with cape in clinical trials.

METHODS: Patients of the Arbeitsgemeinschaft für Internistische Onkologie (AIO) KRK-0IO4 and the Mannheim rectal cancer trial were evaluated. HFSR was graded according to $\mathrm{NCl}-\mathrm{CTC}$ criteria in both trials. Time to first occurrence of HFSR was described per cycle and HFSR developing during cycles I and 2 was defined as 'early HFSR'. Baseline characteristics between the patient groups with or without HFSR were compared using Mann-Whitney- $U$, Fisher's exact or $\chi^{2}$-test, as appropriate. Haematological and nonhaematological toxicities observed in both groups were compared using Fisher's exact test. Progression-free (PFS) or disease-free (DFS) as well as overall survival (OS) data from both trials were pooled and the HFSR group was compared with the non-HFSR using Kaplan-Meier analysis.

RESULTS: A total of 374 patients were included, of whom 29.3\% developed any HFSR. Of these, 5I\% had early HFSR. Baseline characteristics were comparable between both HFSR groups concerning age, gender, ECOG performance status and UICC stage. On multivariate analysis none of these factors had influence on the occurrence of HFSR. The percentage of all-grade (and grade 3-4) haematological toxicities did not differ between both the groups. By contrast, patients exhibiting HFSR had a significantly higher rate of all-grade (but not grade 3-4) diarrhoea, stomatitis/mucositis and fatigue $(P<0.01$, respectively). Patients with HFSR had improved PFS/DFS (29.0 vs II.4 months; $P=0.015$, HR 0.69) and OS (75.8 vs 41.0 months; $P=0.001, H R=0.56$ ). Within the HFSR group, PFS/DFS and OS were comparable between patients with early vs late HFSR.

INTERPRETATION: The present analysis provides evidence for the association of HFSR and survival in patients with colorectal cancer. Baseline characteristics, with the exception of UICC stage, older age and ECOG performance status, and the time of occurrence of HFSR had no impact on survival. Patients with HFSR had a higher probability of developing any-grade gastrointestinal toxicity and fatigue while no correlation with haematological toxicity was found.

British Journal of Cancer (2012) I 07, 1678-1683. doi:I0.1038/bjc.2012.434 www.bjcancer.com

Published online 2 October 2012

(c) 2012 Cancer Research UK

Keywords: capecitabine; hand-foot syndrome; skin; colon cancer; adjuvant; metastatic

Capecitabine (cape) is registered for the treatment of several tumour enitites including colorectal-, gastric- and breast cancer. It is an orally administered 5-fluorouracil (5-FU) prodrug designed to mimic the pharmacokinetics of infusional 5-FU (Schuller et al, 2000). A three-step enzymatic process is necessary to convert cape to the active agent 5-FU (Miwa et al, 1998). The final step is mediated by thymidine phosphorylase, an enzyme frequently expressed in tumour tissues (Toi et al, 2005).

*Correspondence: Professor Dr R-D Hofheinz;

E-mail: ralf.hofheinz@umm.de

Received 25 June 2012; revised 10 August 2012; accepted 31 August 2012; published online 2 October 2012
In stage III colon cancer patients, cape was shown to have at least equivalent activity when compared with bolus 5 -FU/folinic acid (Twelves et al, 2012). In patients with metastatic colorectal cancer it was non-inferior to infusional 5-FU in combination with oxaliplatin-based therapy in the first- and second-line treatment (Rothenberg et al, 2008; Cassidy et al, 2011). Recently, it could be shown that cape can replace 5-FU in the neoadjuvant as well as in the perioperative treatment of patients with locally advanced rectal cancer (Roh et al, 2011; Hofheinz et al, 2012).

Dose modifications and tailoring treatment according to adverse events have a pivotal role in the treatment with cape (Gressett et al, 2006). Hand-foot-skin reaction (HFSR) is regarded as one of the most important adverse events of cape. In clinical studies, the incidence of HFSR was $20-60 \%$. Hand-foot-skin reaction has been 
associated with improved outcome in patients with metastatic breast cancer (Taguchi et al, 2010), and post hoc analyses of the $\mathrm{X}$-ACT and CIOX trials (Stintzing et al, 2011; Twelves et al, 2012) suggest that the occurrence of HFSR was associated with better outcome as well.

Here, we sought to explore the potential association of HFSR with disease/progression-free (PFS) and overall survival (OS) in German patients with colorectal cancer treated in two prospective randomised trials. Moreover, we were interested in the time course of HFSR and in potential associations with clinical factors as well as with other toxicities.

\section{MATERIALS AND METHODS}

In this explorative analysis, patient data of two randomised trials was pooled to evaluate the predictive value of cape-induced HFSR. Therefore, data from a randomised non-inferiority phase III trial (Hofheinz et al, 2012) investigating the efficacy of cape in comparison with 5-FU for the perioperative chemoradiotherapy (CRT) of locally advanced rectal cancer (Mannheim rectal cancer trial) and data from a randomised phase II trial (Moosmann et al, 2011) investigating toxicity and efficacy of CAPOX (cape plus oxaliplatin) and cetuximab vs CAPIRI (cape plus irinotecan) plus cetuximab in the treatment of metastatic colorectal cancer (CIOX trial) were analysed together.

Both trials have already been published as full reports (Moosmann et al, 2011; Hofheinz et al, 2012). Briefly, patients in the rectal cancer trial received six cycles of cape including five cycles with a daily cumulative dose of $2500 \mathrm{mg} \mathrm{m}^{-2}$ cape on days 1-14 given in two equal amounts followed by a 1-week rest period. During radiotherapy, dose was reduced to $1650 \mathrm{mg} \mathrm{m}^{-2}$ per day. Patients could be treated in the adjuvant as well as in the neoadjuvant setting. Toxicity was evaluated every cycle using the NCI-CTCAE (National Cancer Institute Common Toxicity Criteria of Adverse Events) criteria version 2.0. Dose reduction due to toxicity was done according to the manufacturers' recommendation. Between 2002 and 2007, a total of 197 patients were randomised to cape treatment within the rectal cancer trial. Disease-free survival (DFS) and OS were defined by the time from randomisation to the date of disease recurrence (metastasis or local recurrence) and date of death, respectively.

Within the CIOX trial, two different doses of cape were administered depending on the chemotherapy combination partner. In the CAPOX plus cetuximab arm, a daily dose of $2000 \mathrm{mg} \mathrm{m}^{-2}$ cape was given in two equal amounts on days $1-14$ and combined with intravenous infusion of $130 \mathrm{mg} \mathrm{m}^{-2}$ oxaliplatin on day 1 . This was repeated on day 22 . Patients receiving cape in the combination with irinotecan were scheduled to receive a daily dose of $1600 \mathrm{mg} \mathrm{m}^{-2}$ cape in two equal amounts on day 1-14 along with $200 \mathrm{mg} \mathrm{m}^{-2}$ irinotecan on day 1 . Treatment was repeated on day 22 . In both treatment arms, $250 \mathrm{mg} \mathrm{m}^{-2}$ cetuximab was given weekly, starting with a loading dose of $400 \mathrm{mg} \mathrm{m}^{-2}$. Between 2004 and 2006, a total of 177 patients received cape within the CIOX trial and were evaluable for toxicity. Toxicity was evaluated every cycle using NCI-CTCAE criteria version 3.0. Dose reduction due to HFSR was done according to the manufacturers' recommendations. Progression-free survival was evaluated with consistent imaging techniques (CT or MRI) every two cycles (6 weeks). Progression-free survival and OS were calculated from the time of randomisation to the date of progression and date of death, respectively.

\section{Evaluation of HFSR}

Hand-foot-skin reaction was evaluated using the NCI-CTCAE criteria at any cycle. NCI-CTCAE version 2.0 and 3.0 do not differ with regard to graduation of HFSR. Therefore, HFSR data of both clinical trials could be analysed in a pooled analysis. For statistical analyses, the patient cohort without any sign of HFSR (grade 0) was compared with the group showing any sign of HFSR (grade 1-3). Early HFSR was defined by the appearance of any HFSR during the first two cycles of cape treatment. To evaluate the association between the occurrence of HFSR and survival times, OS, DFS- and PFS data of both trials were merged and analysed together.

\section{Statistics}

Within an exploratory analysis the patient cohorts were compared using Fisher's exact test, $\chi^{2}$-test for proportions and MannWhitney $U$-test for continuous variables. Progression-free survival/DFS and OS were determined using the Kaplan-Meier method and log-rank testing.

To compare the impact of different factors on PFS and OS a multivariate Cox proportional hazard regression analysis was performed and corresponding hazard ratios were tested using the Wald test. The association of clinical features to predict HFSR was quantified by using multivariate logistic regression models where the corresponding odds ratios were tested by the Wald test.

All statistical tests were two-sided and a $P$-value $<0.05$ was considered as statistically significant. The level of significance was corrected for multiple testing using Bonferronis' correction. Accordingly, a $P$-value of $<0.0125$ for haematological toxicities and a $P$-value of $<0.01$ for non-haematological toxicities was regarded as statistically significant. R (version 2.11.1, R Foundation, Vienna, Austria) and SPSS PASW 18.0 (SPSS Inc., Chicago, IL, USA) software were used for all statistical analyses.

\section{RESULTS}

\section{Patient characteristics}

Pooled data on toxicity of 374 patients (177 from Arbeitsgemeinschaft für Internistische Onkologie (AIO) CRC-0104 study, 197 from Mannheim rectum trial) was available. Median age of all patients was 63 years (range, $30-85$ years), $n=77$ patients $(20.6 \%)$ were aged $\geqslant 70$ years. A total of $n=358$ patients $(95.7 \%)$ had an ECOG performance status of zero or one, and $n=256$ patients $(68.5 \%)$ were male.

Regarding all patients, $n=111(29.7 \%)$ reported any grade HFSR. The grades were distributed as follows: grade $1 n=43$ $(11.5 \%)$, grade $2 n=52(13.6 \%)$, grade $3 n=14(3.7 \%)$, not specified $n=2(0.5 \%)$. Cumulative occurrence of HFSR is shown in Figure 1, indicating that HFSR occurs as an early event in most patients during treatment with cape. Early HFSR was observed in $56(50.9 \%)$ of patients developing HFSR at any time, and $75 \%$ of patients developed HFSR during the first four cycles of treatment.

Looking at patients' characteristics (Table 1) no significant differences with regard to age, gender, ECOG performance status or UICC stage between the patient cohorts were found.

\section{Correlation of HFSR and survival}

Patients developing HFSR had significantly longer survival times, irrespectively of the UICC stage (Table 2). For the combined analysis of DFS and PFS, patients with HFSR had median survival times of 29.0 months (95\% CI: $0.0-58.5$ months) compared with 11.4 months (95\% CI: 7.1-15.7 months) (log-rank $P=0.015$; HR: 0.69 ) in patients without HFSR (Figure 2A). Similar results could be observed for median OS: 75.8 months (95\% CI not applicable) (HFSR grade 1-3) vs 41.0 months (95\% CI: 31.0-51.0 months) (HFSR grade 0) (log-rank $P<0.001$; HR 0.56) (Figure 2B). Within the patient cohort that developed HFSR at any grade, no significant difference in survival was seen between those developing HFSR within the two cycles of treatment (early HFSR) and those with later onset of HFSR (Figure 3A and B). Owing to crossing survival curves, no log-rank correlation analyses has been performed. 
In multivariate Cox regression analysis, the occurrence of HFSR adjusted for UICC, ECOG performance status and age was identified to be a strong predictor for longer survival (DFS/PFS: HR 0.57 (95\% CI: 0.42-0.77); P<0.001; OS: HR 0.54 (95\% CI: $0.38-$

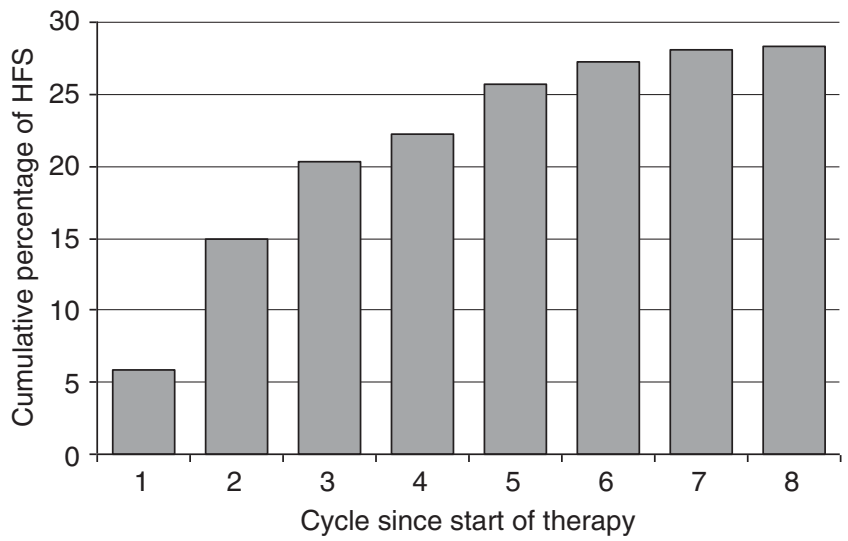

Figure I Cumulative occurrence of HFSR by cycle indicated as proportion of all patients included in analysis. Abbreviation: HFS = handfoot skin reaction

Table I Baseline characteristics ( $n=374$ patients)

\begin{tabular}{|c|c|c|c|}
\hline & $\begin{array}{l}\text { HFSR grade } 0 \\
\quad(n=263)\end{array}$ & $\begin{array}{c}\text { HFSR grade I-3 } \\
(n=1 \mathrm{II})\end{array}$ & $P$ \\
\hline Median age (range) years & $63(30-85)$ & $64(30-80)$ & $0.705^{\mathrm{a}}$ \\
\hline Age > 65 years, $n(\%)$ & $111(68.5)$ & $51(31.5)$ & $0.568^{\mathrm{b}}$ \\
\hline Age $>70$ years, $n(\%)$ & $57(74.0)$ & $20(26.0)$ & $0.485^{b}$ \\
\hline \multicolumn{4}{|l|}{ Gender } \\
\hline Male, n (\%) & $186(72.7)$ & $70(27.3)$ & \multirow[t]{2}{*}{$0.147^{b}$} \\
\hline Female, $n$ (\%) & $77(65.3)$ & $41(34.7)$ & \\
\hline \multicolumn{4}{|l|}{ ECOG-PS } \\
\hline $0, n(\%)$ & $173(70.9)$ & $71(29.1)$ & \multirow[t]{3}{*}{$0.504^{c}$} \\
\hline I, n (\%) & $66(67.3)$ & $32(32.7)$ & \\
\hline $2, n(\%)$ & $13(81.3)$ & $3(18.8)$ & \\
\hline \multicolumn{4}{|l|}{ UICC stage } \\
\hline UICC II/III, n (\%) & $135(68.5)$ & $62(31.5)$ & \multirow[t]{2}{*}{$0.430^{b}$} \\
\hline UICC IV, n (\%) & $128(72.3)$ & $49(27.7)$ & \\
\hline
\end{tabular}

Abbreviations: ECOG-PS = Eastern Cooperative Oncology Group performance status; Grade = NCl-CTCAE grade; HFSR = hand-foot-skin reaction; UICC stage = Union Internationale Contre le Cancer stage. ${ }^{a}$ Mann-Whitney U-test. ${ }^{\text {b Fisher's exact }}$ test. ${ }^{c} \chi^{2}$-test.
0.77); $P=0.001)$. As expected, higher UICC stage, worse ECOG performance status and older age were significant parameters for shorter OS (Figure 4).

\section{Clinical factors predicting HFSR}

In multivariate logistic regression analyses, baseline patient characteristics were used to detect predictors for the occurrence of HFSR. As depicted in Figure 5, no significance for age, gender, ECOG performance status or UICC stage was established.

\section{Correlation of HFSR with other toxicities}

Next to skin toxicity, other haematological and non-haematological toxicities were recorded. As a first step, the incidence of grade 3 and grade 4 toxicities within the group of patients developing HFSR were compared with the group not showing HFSR. A significant difference in the frequency of grade 3-4 toxicities could neither be observed with regard to haematological nor to nonhaematological toxicities (Table 3).

Further analyses exploring all grades of haematological and nonhaematological toxicities revealed a significant difference with higher observed frequency of diarrhoea, stomatitis/mucositis and fatigue in patients with HFSR (Table 4). The frequency of haematological adverse events was not higher in the HFSR group.

\section{DISCUSSION}

The present analysis confirms previous reports that HFSR is a predictor of improved survival in patients with colorectal cancer (Stintzing et al, 2011; Twelves et al, 2012): Using multivariate analysis it could be demonstrated that both, PFS/DFS and OS data was significantly better in patients developing HFSR. The time point of the development of HFSR was not associated with improved survival. Patients developing HFSR during the first two cycles of treatment had no better outcome than patients with late HFSR. Baseline patient characteristics such as age, gender, ECOG status and UICC stage were not found to be associated with the risk of developing a HFSR. This observation is in line with other reports (Zhang et al, 2012). Our analysis revealed that the development of all-grade mucosal toxicities such as stomatitis/ mucositis and diarrhoea was associated with the risk of developing HFSR, whereas no association with haematological toxicities and HFSR was noticed. This may only in part be explained by higher plasma concentrations because one would expect that higher plasma levels of cape and its metabolites would also impact on the probability of developing other toxicities. One might speculate on the higher susceptibility of the mucosal tissue to increased concentrations of the drug compared with haematopoiesis. This observation, however, deserves further analysis in other studies.

Table 2 Survival times in dependence of the occurrence of HFSR

\begin{tabular}{|c|c|c|c|}
\hline $\begin{array}{l}\text { UICC IIIII } \\
\text { DFS }, \text { months }(95 \% \mathrm{Cl}) \\
\text { OS }^{\mathrm{b}} \text {, months }(95 \% \mathrm{Cl})\end{array}$ & $\begin{array}{c}n=135 \\
72.2(64.9-79.4) \\
79.0(72.3-85.6)\end{array}$ & $\begin{array}{c}n=62 \\
69.4(61.4-77.3) \\
80.7(75.5-86.0)\end{array}$ & $\begin{array}{c}0.19,0.67(0.37-1.21) \\
0.016,0.36(0.15-0.86)\end{array}$ \\
\hline $\begin{array}{l}\text { UICC IV } \\
\text { PFS, months }(95 \% \mathrm{Cl}) \\
\text { OS, months }(95 \% \mathrm{Cl})\end{array}$ & $\begin{array}{c}n=128 \\
5.6(4.6-6.4) \\
19.7(15.6-23.8)\end{array}$ & $\begin{array}{c}n=49 \\
9.9(7.9-11.9) \\
32.0(26.9-37.2)\end{array}$ & $\begin{array}{c}<0.0001,0.59(0.40-0.87) \\
0.006,0.54(0.38-0.75)\end{array}$ \\
\hline
\end{tabular}

Abbreviations: $95 \% \mathrm{Cl}=95 \%$ confidence interval; DFS = disease-free survival; Grade =NCl-CTCAE grade; HFSR = hand-foot-skin reaction; HR=hazard ratio; NA = not applicable; OS = overall survival; PFS = progression-free survival; UICC = UICC stage. ${ }^{a}$ Logrank test. ${ }^{\text {b }}$ Mean values as median has not been reached. 
A

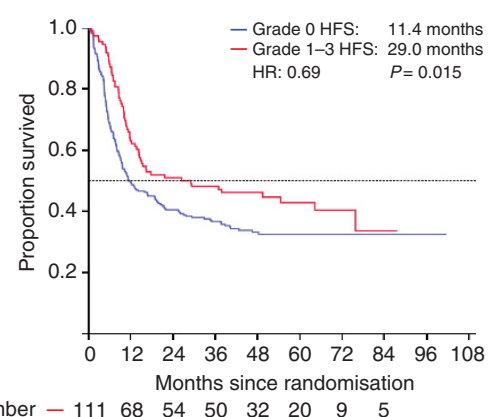

B

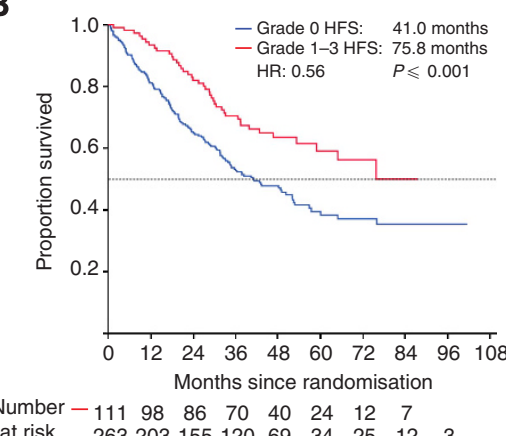

Figure 2 (A) Progression-free/disease-free survival according to the development of HFSR. (B) Overall survival according to the development of HFSR.

A

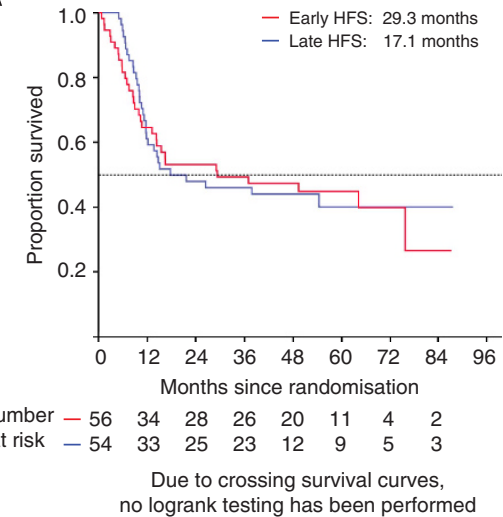

B

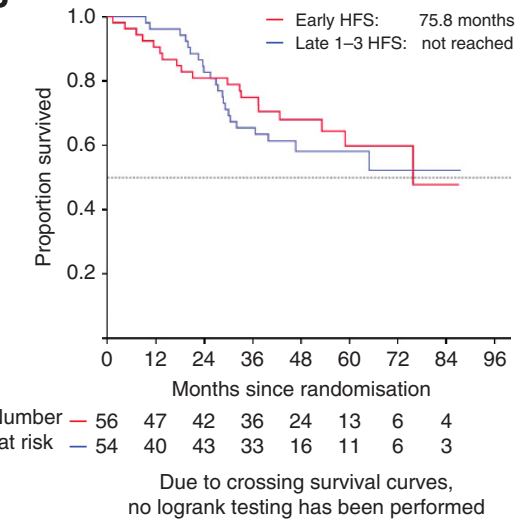

Figure 3 (A) Progression-free/disease-free survival according to the time point of development of HFSR ('early' vs 'late' HFSR). (B) Overall survival according to the development of HFSR ('early' vs 'late' HFSR).

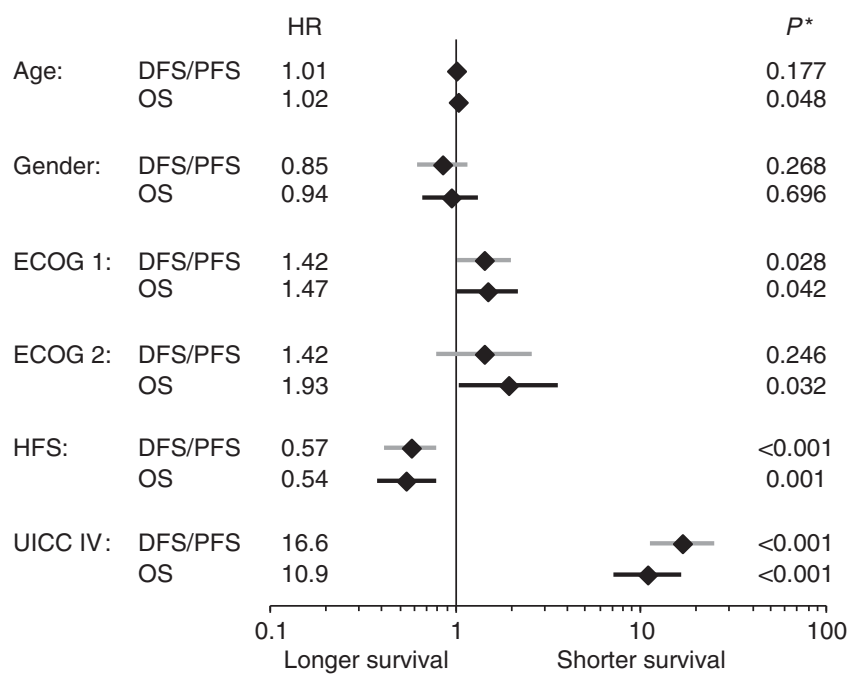

Figure 4 Hazard ratio (HR) to predict PFS/DFS and OS. Abbreviations: age $=$ continuous variable; ECOG $1 / 2=$ Eastern Cooperative Oncology Group performance status 1/2; gender: male $=1$; HFS = hand-foot-skin reaction; UICC IV = union contre le cancer stage IV; * = Wald correlation test.

Compared with earlier reports, the percentage of all-grade HFSR at first glance appears to be lower in the present analysis. For instance, in the X-ACT trial the rate of HFSR was almost twice as high ( $n=613$ out of 1004 patients corresponding to $61.1 \%$ )

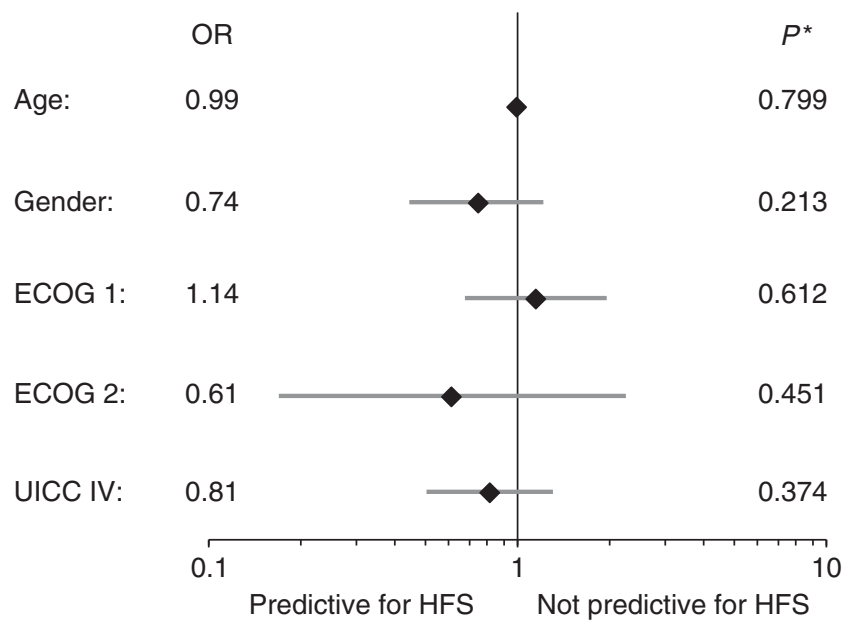

Figure 5 Odds ratio $(O R)$ to predict HFSR. Abbreviations: age $=$ continuous variable; ECOG $1 / 2=$ Eastern Cooperative Oncology Group performance status $1 / 2$; gender: male $=I ;$ UICC IV = union contre le cancer stage IV; ${ }^{*}=$ Wald correlation test.

(Twelves et al, 2005). This might be explained by the lower doses of cape used in the CIOX trial $\left(1600\right.$ or $\left.2000 \mathrm{mg} \mathrm{m}^{-2}\right)$ in comparison with the X-ACT trial $\left(2500 \mathrm{mg} \mathrm{m}^{-2}\right)$. Moreover, in the rectal cancer trial the CRT cycle comprised a daily dose of $1650 \mathrm{mg} \mathrm{m}^{-2}$ resulting in a decreased daily exposure during a 6 -week period. Looking at combination chemotherapy, trials such 
Table $3 \mathrm{NCl}$-CTCAE grade 3 and 4 adverse events according to the development of HFSR

\begin{tabular}{lccc}
\hline & $\begin{array}{c}\text { HFSR grade } \mathbf{0 ,} \\
\mathbf{n}(\%)\end{array}$ & $\begin{array}{c}\text { HFSR grade I-3, } \\
\mathbf{n}(\%)\end{array}$ & $\boldsymbol{P}^{\mathbf{a}}$ \\
\hline Haematologic toxicities & & & \\
$\quad$ Anaemia & $4(1.7)$ & $3(2.7)$ & 0.428 \\
Leukocytopenia & $10(3.8)$ & $1(0.9)$ & 0.185 \\
Thrombocytopenia & $3(1.1)$ & 0 & 0.558 \\
Neutropenic fever & 0 & 0 & $\mathrm{NA}$ \\
& & & \\
Non-haematologic toxicities & $11(4.2)$ & $6(5.4)$ & 0.594 \\
Nausea & $6(2.3)$ & $2(1.8)$ & $>0.99$ \\
Vomiting & $35(13.3)$ & $17(15.3)$ & 0.625 \\
Diarrhoea & 0 & $2(1.8)$ & 0.088 \\
Stomatitis/mucositis & $10(3.8)$ & $5(4.5)$ & 0.776 \\
Fatigue & &
\end{tabular}

Abbreviations: $\quad$ Grade $=\mathrm{NCl}-\mathrm{CTCAE}$ grade; $\mathrm{HFSR}=$ hand-foot-skin reaction;

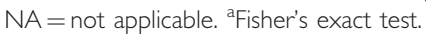

Table $4 \mathrm{NCl}$-CTCAE adverse events of any grade according to the development of HFSR

\begin{tabular}{lccc}
\hline & $\begin{array}{c}\text { HFSR grade 0, } \\
\mathbf{n}(\%)\end{array}$ & $\begin{array}{c}\text { HFSR grade I-3, } \\
\mathbf{n}(\%)\end{array}$ & $\mathbf{P}^{\mathbf{a}}$ \\
\hline Haematological toxicities & & & \\
$\quad$ Anaemia & $138(52.5)$ & $66(59.5)$ & 0.256 \\
Leukocytopenia & $85(32.3)$ & $43(38.7)$ & 0.236 \\
Thrombocytopenia & $68(25.9)$ & $30(27.0)$ & 0.799 \\
Neutropenic fever & $0(0)$ & $0(0)$ & $N A$ \\
Non-haematological toxicities & & & \\
Nausea & $78(29.7)$ & $45(40.5)$ & 0.054 \\
Vomiting & $37(14.1)$ & $19(17.1)$ & 0.526 \\
Diarrhoea & I22(46.4) & $83(74.8)$ & $\leqslant 0.00$ I \\
Stomatitis/mucositis & $30(11.4)$ & $32(28.8)$ & $\leqslant 0.00$ I \\
Fatigue & $81(30.8)$ & $55(49.5)$ & 0.00 I \\
\hline
\end{tabular}

Abbreviations: Grade $=\mathrm{NCl}-\mathrm{CTCAE}$ grade; $\mathrm{HFSR}=$ hand-foot-skin reaction a'Fisher's exact test

as the NO16966 trial including XELOX patients who received cape $2000 \mathrm{mg} \mathrm{m}^{-2}$ a lower rate of HFSR was noticed as well $(n=198 /$ 655 patients corresponding to 30.2\%) (Cassidy et al, 2008). Thus, the rate of HFSR reported in the present analysis is comparable to other trials. The same applies to the time course of development of HFSR. About $75.5 \%$ of patients in the present analysis developed HFSR during the first four cycles of chemotherapy. This corresponds favourably to data recently published by Chinese

\section{REFERENCES}

Cassidy J, Clarke S, Diaz-Rubio E, Scheithauer W, Figer A, Wong R, Koski S, Lichinitser M, Yang TS, Rivera F, Couture F, Sirzen F, Saltz L (2008) Randomized phase III study of capecitabine plus oxaliplatin compared with fluorouracil/folinic acid plus oxaliplatin as firstline therapy for metastatic colorectal cancer. J Clin Oncol 26(12): 2006-2012

Cassidy J, Clarke S, Diaz-Rubio E, Scheithauer W, Figer A, Wong R, Koski S, Rittweger K, Gilberg F, Saltz L (2011) XELOX vs FOLFOX-4 as first-line therapy for metastatic colorectal cancer: NO16966 updated results. $\mathrm{Br} \mathrm{J}$ Cancer 105(1): 58-64

Gressett SM, Stanford BL, Hardwicke F (2006) Management of hand-foot syndrome induced by capecitabine. J Oncol Pharm Pract 12(3): 131-141

Hofheinz RD, Wenz F, Post S, Matzdorff A, Laechelt S, Hartmann JT, Muller L, Link H, Moehler M, Kettner E, Fritz E, Hieber U, Lindemann investigators who showed that about $80 \%$ of cape patients developing HFSR had experienced this adverse event by cycle 4 (data extrapolated from Kaplan-Meier plot; cf. Zhang et al (2012).

With the exception of one trial, clinical studies have failed to demonstrate a benefit of supportive prophylactic measures and treatments of cape-related HFSR. Pyridoxine was ineffective in a Korean randomised trial in 360 patients (Kang et al, 2010). Similarly, the topical use of a urea/lactic-acid-based keratolytic agent in a randomised double-blind trial in 137 patients treated with cape in the United States of America was found to be ineffective (Wolf et al, 2010). Recently, celecoxib at a dose of $200 \mathrm{mg}$ twice a day was reported to reduce the overall incidence of HFSR from 74.6 to $57.4 \%$ in Chinese patients receiving XELOX or cape monotherapy (Zhang et al, 2012). Several methodological shortcomings of the trial (for instance: no patient-reported outcome data, no efficacy data, study conducted at a single centre), and the uncertainty if the results from an Asian patient group may be transferred to Caucasian patients along with potential cardiovascular risks of celecoxib raise doubts as to whether these results should change current clinical practice. Thus, dose reduction and treatment interruption remain the definitive therapies for HFSR.

The primary problem in the prevention of HFSR is that the pathogenesis of HFSR has not been fully elucidated yet. Handfoot-skin reaction is frequently considered as a type of inflammation (Gressett et al, 2006), but recent data indicate that HFSR may be caused by a reduction in the antioxidative potential of the skin due to intensive radical formation. The latter was demonstrated to be caused by the excretion of parts of cytotoxic agents with the sweat onto the skin surface spreading there homogeneously and penetrating into the stratum corneum. This led to disturbance preferably in 'vulnerable' body areas with thick stratum corneum such as the palm and the planta (Kluschke et al, 2012; Lademann et al, 2012). Having said, this may point towards new prophylactic measures for the prevention of HFSR using antioxidant containing ointments with high radical protection factor. The German AIO has recently started a randomised trial investigating a new topical antioxidative cream (Mapisal, medac GmbH, Wedel, Germany), which has been licensed as medical device in Germany.

In summary, our results indicate that the development of HFSR may be regarded as independent clinical predictor of improved survival in patients with colorectal cancer regardless of the time point of HFSR development. Testing individual dose optimisation or titration of cape according to the development HFSR may therefore be an appealing strategy for future studies.

\section{ACKNOWLEDGEMENTS}

We are indebted to Roche Pharma, Germany for providing a grant to enable publication of this work as 'open acces' publication.
HW, Grunewald M, Kremers S, Constantin C, Hipp M, Hartung G, Gencer D, Kienle P, Burkholder I, Hochhaus A (2012) Chemoradiotherapy with capecitabine versus fluorouracil for locally advanced rectal cancer: a randomised, multicentre, non-inferiority, phase 3 trial. Lancet Oncol 13(6): 579-588

Kang YK, Lee SS, Yoon DH, Lee SY, Chun YJ, Kim MS, Ryu MH, Chang HM, Lee JL, Kim TW (2010) Pyridoxine is not effective to prevent handfoot syndrome associated with capecitabine therapy: results of a randomized, double-blind, placebo-controlled study. J Clin Oncol 28(24): 3824-3829

Kluschke F, Martschick A, Darvin ME, Zastrow L, Chekerov R, Lademann J, Sehouli J (2012) Application of an ointment with high radical protection factor as a prevention strategy against PPE. J Clin Oncol 30(suppl): abstr 5064 
Lademann J, Martschick A, Darvin ME, Kluschke F, Zastrow L, Chekerov R, Sehouli J (2012) Treatment of patients with chemotherapy-induced PPE using a prevention ointment containing high concentrations of antioxidants. J Clin Oncol 30(suppl): abstr e19558

Miwa M, Ura M, Nishida M, Sawada N, Ishikawa T, Mori K, Shimma N, Umeda I, Ishitsuka H (1998) Design of a novel oral fluoropyrimidine carbamate, capecitabine, which generates 5-fluorouracil selectively in tumours by enzymes concentrated in human liver and cancer tissue. Eur J Cancer 34(8): 1274-1281

Moosmann N, von Weikersthal LF, Vehling-Kaiser U, Stauch M, Hass HG, Dietzfelbinger H, Oruzio D, Klein S, Zellmann K, Decker T, Schulze M, Abenhardt W, Puchtler G, Kappauf H, Mittermuller J, Haberl C, Schalhorn A, Jung A, Stintzing S, Heinemann V (2011) Cetuximab plus capecitabine and irinotecan compared with cetuximab plus capecitabine and oxaliplatin as first-line treatment for patients with metastatic colorectal cancer: AIO KRK-0104-a randomized trial of the German AIO CRC study group. J Clin Oncol 29(8): $1050-1058$

Roh MS, Yothers GA, O'Connell MJ, Beart RW, Pitot HC, Shields AF, Parda DS, Sharif S, Allegra CJ, Petrelli NJ, Landry JC, Ryan DP, Arora A, Evans TL, Soori GS, Chu L, Landes RV, Mohiuddin M, Lopa S, Wolmark N (2011) The impact of capecitabine and oxaliplatin in the preoperative multimodality treatment in patients with carcinoma of the rectum: NSABP R-04. J Clin Oncol 29(suppl): abstr 3503

Rothenberg ML, Cox JV, Butts C, Navarro M, Bang YJ, Goel R, Gollins S, Siu LL, Laguerre S, Cunningham D (2008) Capecitabine plus oxaliplatin (XELOX) versus -fluorouracil/folinic acid plus oxaliplatin (FOLFOX-4) as second-line therapy in metastatic colorectal cancer: a randomized phase III noninferiority study. Ann Oncol 19(10): 1720-1726

Schuller J, Cassidy J, Dumont E, Roos B, Durston S, Banken L, Utoh M, Mori K, Weidekamm E, Reigner B (2000) Preferential activation of capecitabine in tumor following oral administration to colorectal cancer patients. Cancer Chemother Pharmacol 45(4): 291-297

Stintzing S, Fischer von Weikersthal L, Vehling-Kaiser U, Stauch M, Hass HG, Dietzfelbinger H, Oruzio D, Klein S, Zellmann K, Decker T, Schulze M, Abenhardt W, Puchtler G, Kappauf H, Mittermuller J, Haberl C, Giessen C, Moosmann N, Heinemann V (2011) Correlation of capecitabine-induced skin toxicity with treatment efficacy in patients with metastatic colorectal cancer: results from the German AIO KRK0104 trial. Br J Cancer 105(2): 206-211

Taguchi T, Nakayama T, Masuda N, Yoshidome K, Akagi K, Nishida Y, Yoshikawa Y, Ogino N, Abe C, Sakamoto J, Noguchi S (2010) Study of low-dose capecitabine monotherapy for metastatic breast cancer. Chemotherapy 56(2): 166-170

Toi M, Atiqur Rahman M, Bando H, Chow LW (2005) Thymidine phosphorylase (platelet-derived endothelial-cell growth factor) in cancer biology and treatment. Lancet Oncol 6(3): 158-166

Twelves C, Scheithauer W, McKendrick J, Seitz JF, Van Hazel G, Wong A, Diaz-Rubio E, Gilberg F, Cassidy J (2012) Capecitabine versus 5-fluorouracil/ folinic acid as adjuvant therapy for stage III colon cancer: final results from the X-ACT trial with analysis by age and preliminary evidence of a pharmacodynamic marker of efficacy. Ann Oncol 23(5): 1190-1197

Twelves C, Wong A, Nowacki MP, Abt M, Burris 3rd H, Carrato A, Cassidy J, Cervantes A, Fagerberg J, Georgoulias V, Husseini F, Jodrell D, Koralewski P, Kroning H, Maroun J, Marschner N, McKendrick J, Pawlicki M, Rosso R, Schuller J, Seitz JF, Stabuc B, Tujakowski J, Van Hazel G, Zaluski J, Scheithauer W (2005) Capecitabine as adjuvant treatment for stage III colon cancer. N Engl J Med 352(26): 2696-2704

Wolf SL, Qin R, Menon SP, Rowland Jr. KM, Thomas S, Delaune R, Christian D, Pajon Jr. ER, Satele DV, Berenberg JL, Loprinzi CL (2010) Placebo-controlled trial to determine the effectiveness of a urea/lactic acid-based topical keratolytic agent for prevention of capecitabineinduced hand-foot syndrome: North Central Cancer Treatment Group Study N05C5. J Clin Oncol 28(35): 5182-5187

Zhang RX, Wu XJ, Wan DS, Lu ZH, Kong LH, Pan ZZ, Chen G (2012) Celecoxib can prevent capecitabine-related hand-foot syndrome in stage II and III colorectal cancer patients: result of a single-center, prospective randomized phase III trial. Ann Oncol 23(5): 1348-1353

(c) (i) (2) This work is licensed under the Creative Commons

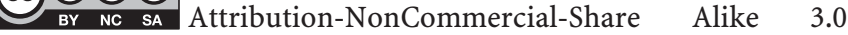
Unported License. To view a copy of this license, visit http:// creativecommons.org/licenses/by-nc-sa/3.0/ 